\title{
Immunization, urbanization and slums - a systematic review of factors and interventions
}

\author{
Tim Crocker-Buque ${ }^{1 *}$, Godwin Mindra ${ }^{2}$, Richard Duncan $^{2}$ and Sandra Mounier-Jack ${ }^{1}$
}

\begin{abstract}
Background: In 2014, over half (54\%) of the world's population lived in urban areas and this proportion will increase to $66 \%$ by 2050 . This urbanizing trend has been accompanied by an increasing number of people living in urban poor communities and slums. Lower immunization coverage is found in poorer urban dwellers in many contexts. This study aims to identify factors associated with immunization coverage in poor urban areas and slums, and to identify interventions to improve coverage.
\end{abstract}

Methods: We conducted a systematic review, searching Medline, Embase, Global Health, CINAHL, Web of Science and The Cochrane Database with broad search terms for studies published between 2000 and 2016.

Results: Of 4872 unique articles, 327 abstracts were screened, leading to 63 included studies: 44 considering factors and 20 evaluating interventions (one in both categories) in 16 low or middle-income countries. A wide range of socio-economic characteristics were associated with coverage in different contexts. Recent rural-urban migration had a universally negative effect. Parents commonly reported lack of awareness of immunization importance and difficulty accessing services as reasons for under-immunization of their children. Physical distance to clinics and aspects of service quality also impacted uptake. We found evidence of effectiveness for interventions involving multiple components, especially if they have been designed with community involvement. Outreach programmes were effective where physical distance was identified as a barrier. Some evidence was found for the effective use of SMS (text) messaging services, community-based education programmes and financial incentives, which warrant further evaluation. No interventions were identified that provided services to migrants from rural areas.

Conclusion: Different factors affect immunization coverage in different urban poor and slum contexts. Immunization services should be designed in collaboration with slum-dwelling communities, considering the local context. Interventions should be designed and tested to increase immunization in migrants from rural areas.

Keywords: Vaccine, Immunization, Urban, Slum, Low-income

\section{Background}

In 2014, over half (54\%) of the world's population lived in urban areas [1]. By 2050 this proportion is expected to increase to $66 \%$, adding approximately 2.5 billion new urban dwellers, of whom $90 \%$ will be in Asia and Africa [2]. This trend towards urbanization is closely linked with an increasing population living in urban poor communities and slum environments [2]. Although the

\footnotetext{
* Correspondence: timothy.crocker-buque@lshtm.ac.uk

${ }^{1}$ Health Protection Research Unit in Immunisation, Faculty of Public Health

and Policy, London School of Hygiene and Tropical Medicine, 15-17

Tavistock Place, London WC1H 9SH, UK

Full list of author information is available at the end of the article
}

proportion of urban residents living in slums has been decreasing, the absolute number has increased substantially, from 689 million in 1990 to 880 million in 2014, and is expected to double by 2030 [3]. In order to meet the outcomes in the New Urban Agenda and Sustainable Development Goals to improve health for slum-dwellers a better understanding is needed of each individual slum environment and the factors contributing to poor health outcomes $[4,5]$. 


\section{Immunization and urbanization}

Significant disparities exist in immunization coverage in urban areas with lower coverage observed in the urban poor in many countries (Fig. 1).

Although some countries, such as Bangladesh, have achieved immunization equity, these disparities are growing in many others, including Nigeria, Ethiopia, Cameroon and Pakistan [6]. However, Demographic Health Surveys do not sample urban slums specifically Tables 1 and 2. display the results of recent studies that have reported data on immunization coverage in slums in India and in subSaharan African countries, showing a wide range of coverage, from $3.0 \%$ and $8.5 \%$ in rural migrant children in slums in Chandigarh and Nigeria $[7,8]$, to $88.7 \%$ and 93.3\% in Mumbai and Ouagadougou $[9,10]$.

Where immunization coverage is low Vaccine Preventable Diseases (VPDs) contribute to worse health outcomes in poor urban populations, particularly in slums. Increased morbidity and mortality has been observed from measles [11, 12], mumps [13], diphtheria [14], influenza [15], and typhoid [16-19]; in slums in: South Africa [11], India [12, 13, 17, 19], Bangladesh [15, 18] and Kenya [16]. Outbreaks of VPDs are more common in urban slums than in other urban areas and have a larger number of cases secondary to high population density and continuous influx of a new pool of infective agents with migratory populations $[11-14,19]$. Crowding is known to increase childhood mortality from VPDs [20,21].

In addition, vaccine programmes designed for a general population may not be as effective in urban slums, which are characterized by lack of essential infrastructure (such as electricity and water), poor housing quality and where residents may be recent migrants, or have insecure legal or residential status, limiting access to basic health services, if they are available at all $[22,23]$.
Although low immunization coverage is not inevitable amongst the urban poor, there is no current systematic synthesis describing the associated demographic, geographic, and socio-economic factors, nor considering interventions to increase coverage. Therefore, the aim of this study is to identify the factors associated with immunization coverage in low-income urban areas and slums in low and middleincome countries (LMICs), and identify the evidence for interventions to improve coverage.

\section{Methods}

We conducted a systematic review in line with the Preferred Reporting Items for Systematic Reviews and Meta-Analysis (PRISMA) statement [24].

\section{Search strategy}

We searched Medline, Embase, Global Health, CINAHL, Web of Science and The Cochrane Database of Systematic Reviews, using the strategy shown in Additional file 1.

\section{Inclusion and exclusion criteria}

Studies published between 2000 and July 2016 with the following characteristics were included:

- Population: any population living in a low-income urban area or slum in a LMIC [25]. Slums have a broad operational definition, so we have included consideration of urban poor communities that have slum-like characteristics, even if they have not been formally designated as a slum [22].

- Study design:

- Observational studies: cross-sectional surveys and cohort studies, designed to identify factors associated with coverage levels.

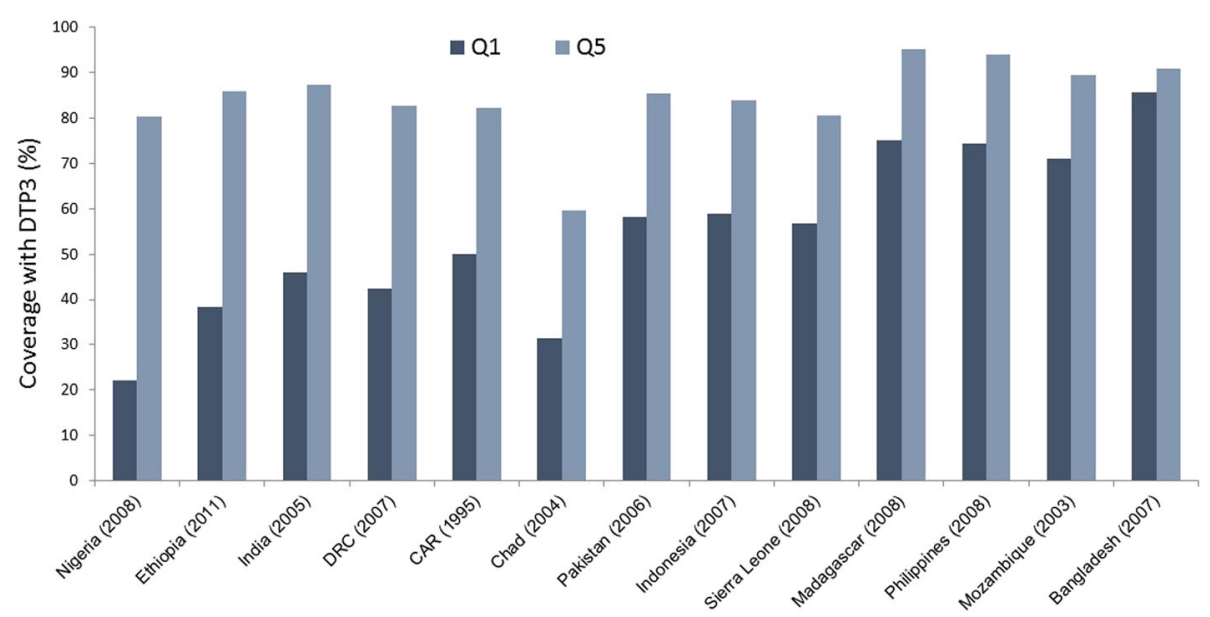

Fig. 1 DTP3 coverage in selected countries ranked in order of difference between wealth quintilesDTP3 = 3rd dose of diphtheria, tetanus and pertussis vaccine. Q1 = poorest and Q5 = wealthiest urban wealth quintiles. Data from WHO Observatory [105] 
Table 1 Showing studies conducted in slum populations in sub-Saharan Africa reporting immunization status of children since 2000

\begin{tabular}{|c|c|c|c|c|c|c|c|c|c|}
\hline \multirow[t]{2}{*}{ Ref } & \multirow[t]{2}{*}{ First Author } & \multirow[t]{2}{*}{ Year } & \multirow[t]{2}{*}{ Population } & \multirow[t]{2}{*}{ Country } & \multirow{2}{*}{$\begin{array}{l}\text { Sample } \\
\text { size }\end{array}$} & \multicolumn{3}{|c|}{ Immunization Status (\%) } & \multirow[t]{2}{*}{ Notes } \\
\hline & & & & & & Complete & Partial & Unimmunized & \\
\hline [10] & $<<$ Soura & 2015 & Children 12-59 months & Burkina Faso & 3103 & 93.3 & 6.7 & & \\
\hline [65] & Maina & 2013 & Children 12-23 months & Kenya & 380 & 76.6 & 23.4 & & \\
\hline [64] & Egondi & 2015 & Children 12-23 months & Kenya & 382 & 70.0 & 30.0 & & \\
\hline [73] & Bobossi-Serengibé & 2014 & Children $<11$ months & CAR & 400 & 67.0 & 33.0 & & \\
\hline [66] & Mutua & 2011 & Children $12-23$ months & Kenya & 1848 & 58.0 & 42.0 & & \\
\hline [10] & $<<$ Soura & 2015 & Children 12-59 months & Kenya & 1369 & 55.0 & 45.0 & & \\
\hline [72] & Mohamud & 2014 & Children $12-23$ months & Ethiopia & 582 & 47.6 & 32.7 & 19.7 & $\begin{array}{l}\text { Low-income urban } \\
\text { (not slum specifically) }\end{array}$ \\
\hline [8] & Fatiregun & 2013 & Children $12-23$ months & Nigeria & 588 & 38.8 & 45.6 & 15.7 & $\begin{array}{l}\text { Low-income urban } \\
\text { (not slum specifically) }\end{array}$ \\
\hline \multirow[t]{3}{*}{ [71] } & $\wedge$ Antai & 2012 & Children $>12$ months & Nigeria & 604 & 24.3 & 75.7 & & Rural \\
\hline & $\wedge$ Antai & 2012 & Children $>12$ months & Nigeria & 593 & 15.2 & 84.8 & & Urban \\
\hline & $\wedge$ Antai & 2012 & Children $>12$ months & Nigeria & 1303 & 8.5 & 91.5 & & Rural-Urban migrant \\
\hline
\end{tabular}

$<<$ and $\wedge$ denote results from the same study disaggregated by urban, rural or migration status

Table 2 Showing studies conducted in slum populations in India reporting immunization status of children since 2000

\begin{tabular}{|c|c|c|c|c|c|c|c|c|c|}
\hline \multirow[t]{2}{*}{ Ref } & \multirow{2}{*}{$\begin{array}{l}\text { First } \\
\text { Author }\end{array}$} & \multirow[t]{2}{*}{ Year } & \multirow[t]{2}{*}{ Population } & \multirow[t]{2}{*}{ Location } & \multirow{2}{*}{$\begin{array}{l}\text { Sample } \\
\text { size }\end{array}$} & \multicolumn{3}{|c|}{ Immunization Status (\%) } & \multirow[t]{2}{*}{ Notes } \\
\hline & & & & & & Complete & Partial & Unimmunized & \\
\hline [9] & Kulkarni & 2013 & Children 12-23 months & Mumbai & 352 & 88.7 & & 11.9 & $\begin{array}{l}\text { Complete or } \\
\text { incomplete }\end{array}$ \\
\hline [101] & Damor & 2013 & Children $1-5$ years & Jamnagar & 450 & 75.0 & 13.3 & 11.6 & \\
\hline [39] & Kadarkar & 2016 & Children 12-23 months & Mumbai & 336 & 75.0 & 22.3 & 2.7 & \\
\hline [45] & Trivedi & 2014 & Children $12-23$ months & Rewa & 210 & 72.4 & 21.9 & 5.7 & \\
\hline$[56]$ & Kar & 2001 & Children 12-23 months & South Delhi & 166 & 69.3 & 15.7 & 15.1 & \\
\hline [49] & Wadgave & 2012 & Children $<5$ years & Solapur & 420 & 64.3 & 25.6 & 9.8 & \\
\hline [53] & >Kusuma & 2010 & $\begin{array}{l}\text { Rural-urban migrant } \\
\text { children up to } 2 \text { years }\end{array}$ & Delhi & 746 & 60.2 & 34.9 & 4.9 & Settled migrants \\
\hline$[40]$ & Awasthi & 2015 & Children 12-23 months & Varanasi & 384 & 57.0 & & 43.0 & $\begin{array}{l}\text { Complete or } \\
\text { incomplete }\end{array}$ \\
\hline [41] & Khan & 2015 & Children 12-23 months & Jagdalpur & 225 & 55.1 & 30.7 & 14.2 & \\
\hline$[57]$ & Desai & 2003 & Children 9-59 months & Surat & 3035 & 49.3 & & 51.7 & Measles only \\
\hline$[50]$ & Sachdeva & 2012 & Children 12-23 months & New Delhi & 210 & 47.8 & 17.2 & 35.2 & Hep B only \\
\hline [42] & Kulkarni & 2014 & Children 12-23 months & Hyderabad & 510 & 44.1 & 32.0 & 23.9 & \\
\hline [54] & Nath & 2007 & Children 12-23 months & Lucknow & 510 & 44.1 & 32.0 & 23.9 & \\
\hline [44] & Agarwal & 2014 & Children $<5$ years & Kanpur & 390 & 41.4 & 44.8 & 13.8 & \\
\hline [53] & >Kusuma & 2010 & $\begin{array}{l}\text { Rural-urban migrant } \\
\text { children up to } 2 \text { years }\end{array}$ & Delhi & 746 & 39.7 & 54.8 & 5.5 & Recent migrants \\
\hline [102] & Gupta & 2012 & Children $<5$ years & Bhopal & 790 & 35.2 & 48.2 & $\mathrm{n} / \mathrm{a}$ & $16.4 \%$ status unknown \\
\hline$[47]$ & Angandi & 2013 & Children 12-23 months & Bijapur & 155 & 34.8 & 62.6 & 2.6 & \\
\hline$[52]$ & Jain & 2010 & Children 12-23 months & Meerut & 216 & 31.0 & 17.1 & 51.9 & \\
\hline [103] & Sharma & 2009 & Children 12-23 months & Surat & 300 & 25.1 & 51.7 & 23.1 & \\
\hline$[55]$ & Mathew & 2002 & Children $<5$ years & New Delhi & 500 & 25.0 & 44.4 & 30.6 & \\
\hline [7] & \#Sharma & 2015 & Children 12-23 months & Chandigarh & 310 & 23.0 & 73.0 & 3.0 & Non-migrants \\
\hline [51] & Ghei & 2010 & Children 10-23 months & Agra & 1728 & 14.0 & 45.0 & 41.0 & \\
\hline [7] & \#Sharma & 2015 & Children 12-23 months & Chandigarh & 310 & 3.0 & 91.0 & 6.0 & Migrants \\
\hline
\end{tabular}


- Intervention studies: randomised controlled trials (RCTs), quasi-experimental (including time-series and before-and-after studies) and ecological designs that evaluated any intervention designed to increase vaccine uptake or coverage, including any associated economic analyses.

In addition, we included primary studies identified from searching the references from other review articles identified in the search that fitted inclusion criteria.

\section{Study selection process}

One reviewer screened articles by title and manually deduplicated records. Two reviewers screened potentially relevant abstracts independently. Any disagreement was resolved by discussion, based on the inclusion criteria. Three reviewers agreed the final inclusions.

\section{Results}

Of 4872 unique articles, 327 abstracts were screened, leading to 80 full text articles being reviewed, along with nine additional studies identified from the references of 12 review articles [6, 26-36]. In total 63 studies were included (Fig. 2). Forty-four studies looked at factors associated with immunization coverage and 20 studies evaluated interventions. One study appears in both categories.

\section{Factors associated with immunization coverage}

The qualitative synthesis of factors identified from 44 studies is presented below, categorized into 4 groups: socio-economic characteristics; migration status; information, beliefs and behavior; and health services. All studies were cross-sectional surveys, aside from one qualitative study [37], and one ecological study [38]. Quantitative synthesis of measures of effect was not able to be performed due to heterogeneity in study design, population and methods.

Studies were conducted in populations in India $(n=23)$ [7, 9, 38-58], Pakistan $(n=3)$ [59-61], Iran $(n=1)$ [62], China $(n=1)$ [63], Kenya $(n=6)$ [10, 64-68], Nigeria $(n=4)[8,69-71]$, Burkina Faso $(n=1)$ [10], Ethiopia $(n=1)$ [72], Democratic Republic of Congo $(\mathrm{DRC})(n=1)$ [37], Central African Republic (CAR) $(n=1)$ [73], Zambia $(n=1)$ [74], and Brazil $(n=2)[75,76]$,

\section{Socio-economic and demographic characteristics}

Socio-economic (SE) status was measured in a variety of ways, including using measures of wealth or income, employment status, education, or surrogate markers like receipt of government payments.

In India, the impact of SE factors has been studied extensively in low-income urban and slum areas. An ecological study using data from the Indian National Family Health Survey showed that the children in the lowest wealth quartile in urban areas have significantly lower coverage (around 40\%) than in any other urban wealth group [38]. Another study examined the survey data in more detail to compare a wider range of SE factors and outcomes of 1877 children in less developed Empowered Action Group states with more developed northern counterparts and found that having an illiterate mother or father, poverty, and being a 3rd born child or greater had the greatest effect on immunization coverage [46]. However, studies conducted in individual locations paint a more heterogeneous picture. Mothers' education was associated with lower coverage in some studies $[39,49,51]$, but not in others $[45,53]$. Similarly, female children had lower coverage in some studies $[39,45,51]$, but no gender difference was found in others $[9,49,50]$. In one study malnutrition was also found to be much more common in unimmunized slumdwelling children [44].

Elsewhere, a study in a slum in Karachi, Pakistan, found lower coverage in lower SE groups [59]. However, the study reported a much more significant effect of being from a marginalized ethnic group, particularly if associated with illegal or insecure residential status. Another study in Pakistan found mothers' education was a significant predictor of measles containing vaccine (MCV) coverage in urban areas [60]. However, the impact of other SE factors was different in different localities.

The findings from sub-Saharan African countries are similar in their diversity. Across 3 slum populations in Kenya factors associated with immunization coverage included: maternal education, employment and age; child's birth order; number of children, place of birth; and household assets and expenditure [64-66]. Ethnic group was a significant predictor of MCV uptake in Nairobi [67]. A paired study conducted in slums in Nairobi and Ouagadougou found that while the SE factors in each slum were similar, children in Nairobi were 11.5 times more likely to be unvaccinated, suggesting a powerful environmental effect [10]. In Jigjiga, Ethiopia, maternal age and literacy, place of residence, tetanus immunization status, place of delivery and household visit by health workers were the most important predictors of completing immunization [72].

In Sao Palo, Brazil, a study of 258 children in a philanthropic day care centre found premature birth, malnourishment, inadequate housing and poor prenatal care to be associated with lower coverage [75]. However, a larger Brazilian study involving 17,000 children found that those in lower SE groups had higher immunization rates than their wealthier peers [76]. Although this association is not fully explained in the paper, the authors found that parents in higher socioeconomic quintiles had higher vaccine refusal rates and hypothesize that progressive reduction in 


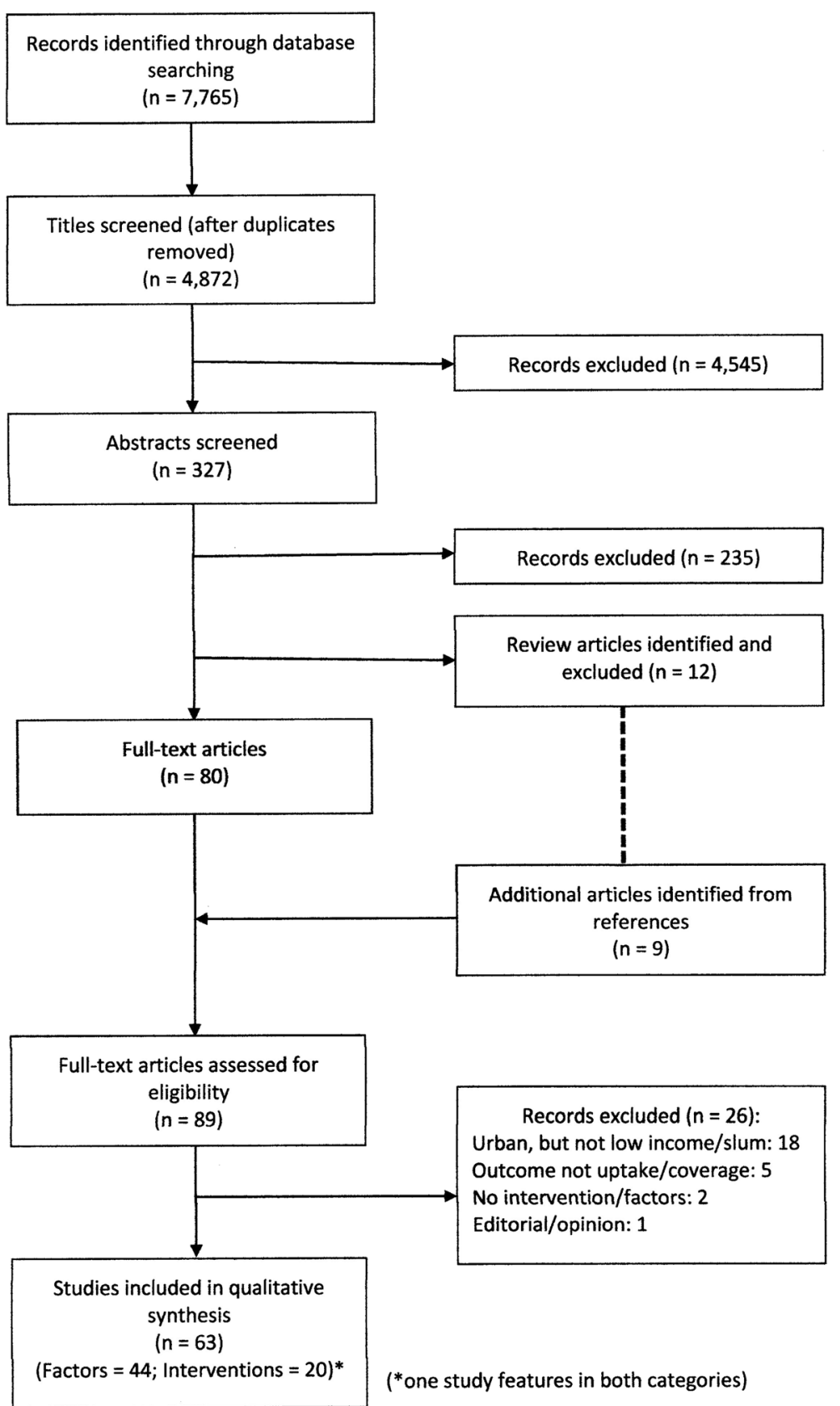

Fig. 2 PRISMA flowchart of literature selection

VPD incidence over many years may have led to complacency, alongside unfounded vaccine safety concerns widely reported in other countries.

\section{Migration status}

Four studies demonstrated a negative effect of migration status on immunization coverage in India $[7,53]$, China [63], and Nigeria [71]. In India, recent migrants were found to have lower coverage than settled migrants (living in new urban location for $>12$ months), which then resolved to the slum-area average over time [53]. A study comparing reasons for under-immunization given by migrant and non-migratory parents in an Indian slum cited mother or both parents being too busy; parent returned to home village; parent unaware of place or time of immunization; and lack of awareness for the need for immunization as the main reasons for underimmunization [7]. In Nigeria, children of urban nonmigrant mothers had $67 \%$ higher chance of being fully immunized than migrant children, which was attributed 
to the disrupting force of migration [71]. However, other characteristics, including: children being of higher birth order; being a mother aged $<18$ years; and lower SE status, also played a significant role, independent of migration status after regression modelling. Thus, there are elements of similarity of the risks of low immunization coverage as faced by all urban poor communities, but these are exacerbated by the disruptive force of migration.

\section{Information, beliefs and behavior}

Many studies that collected information on SE characteristics also asked parents why their children were not fully vaccinated. In India, frequently identified reasons included: unaware of the need for vaccines; $[7,9,39,40,42,45,47,49,50,52,54,56,57]$ parents being too busy; $[7,9,39,42,54,55]$ traveled to place of origin; [7, 39, 54-56] and unaware of clinic location or timing [7, 9, 42, 47, 52, 54].

Unfortunately, there are fewer studies available from other countries to make similar comparisons. In two studies conducted in Pakistan, maternal knowledge of immunization was an important factor; [61] and the reasons for under-immunization given by mothers were to do with 'carelessness' or difficulty in accessing services [60]. In Ibadan, Nigeria, a study found fear of sideeffects, maternal awareness, and parents being too busy to attend clinic to be significant; [8] in neonates in Benin City, Nigeria, a study found that SE and education status were associated with delayed immunization; [69] and the 3 main reasons for under-vaccination identified in a study from Bangui, Central African Republic, were the mother being too busy, negative attitude of health workers, and lack of access to information [73].

One qualitative study conducted in a slum in DRC investigated health service access using focus group interviews [37]. It painted a detailed picture of parents conflicting views and beliefs, including concerns over out-of-pocket expenditure and being suspicious of free services (including vaccines), while seeing some services as beneficial, but not acceptable due to lack of information and distrust in the government.

\section{Health services}

A study that used mapping techniques to evaluate health service access in Agra, India, found that the presence of a health center within $2 \mathrm{~km}$ of the slum doubled the chances of a child being completely immunized [51]. A similar study in Lusaka, Zambia, showed that further distance from service points were associated with lower coverage [74]. Timing of services is also important, where offering services only on one particular day is associated with reduced coverage in neonates in Nigeria [69]. However, slum-dwelling populations may also be less likely to access health services due to fear of costs, risk of lost income, or lack of local knowledge [48]. A study from Nigeria showed that even when services are provided free, urban dwellers consume less than their rural counterparts [70]. However, another study found a high level of payment for services that should have been provided for free, including immunization and pre-natal care. This may be a common experience in LMICs, due to low payments made to health workers, and when present, may affect the long-term effectiveness of vaccine programmes. However, when people do access healthcare higher patient satisfaction and provision of accurate information was shown to lead to increased attendance for repeat vaccine doses in an Indian slum community [58]. Accessing pre-natal care was shown to have a positive impact on immunization coverage in India [41], Ethiopia [72], and Brazil [75].

A missed vaccination opportunity is when health workers interact with a child who is under-immunized and could have been offered a vaccination, but for some reason do not [27]. A study conducted in 6 health facilities in a Nairobi slum found that vaccine coverage could have been increased if all missed vaccination opportunities had been taken [68].

\section{Interventions}

Twenty studies were identified that looked at interventions to increase immunization uptake and are displayed in Table 3 . These were conducted in India $(n=5)$ [77-81], Pakistan $(n=5)$ [82-86], Bangladesh $(n=3)$ [87-89], Zambia $(n=2)$ [74, 90], Uganda $(n=1)$ [91], Kenya $(n=1)$ [92], Brazil $(n=1)$ [93], Guatemala $(n=1)$ [94], and Mongolia $(n=1)$ [95].

We have divided them into five categories: multicomponent interventions $(n=8)$; outreach programs $(n=4)$; reminder/recall systems $(n=4)$; education $(n=2)$; and those considering incentives $(n=2)$

\section{Multi-component interventions}

We found evidence of effectiveness for interventions involving multiple components designed to meet the specific needs of a slum-dwelling community, especially if they have been designed and delivered with community involvement.

Two related studies reported on an intervention conducted in Dhaka, Bangladesh. The first is a noncontrolled before-and-after evaluation of the intervention comprising four components: extended services hours; provider training; a screening tool; and a community support group [88]. Analysis of 529 children before and 526 after the intervention showed increased coverage over 12 months, with complete immunization rising from $43 \%$ to $99 \%$. The second study calculated the cost of the programme at $\$ 20.95$ per fully immunized child [87]. A similar programme in low-income areas 


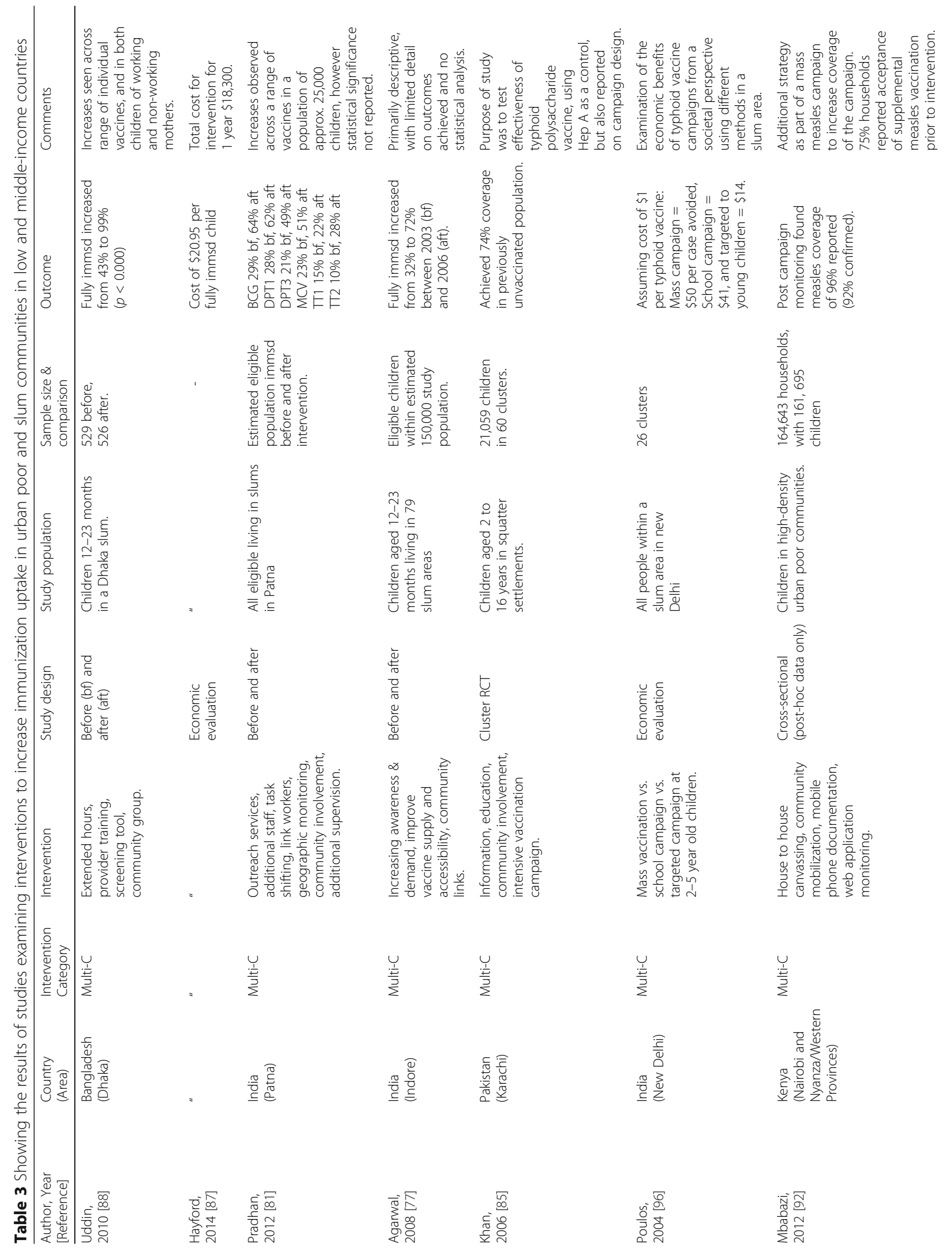




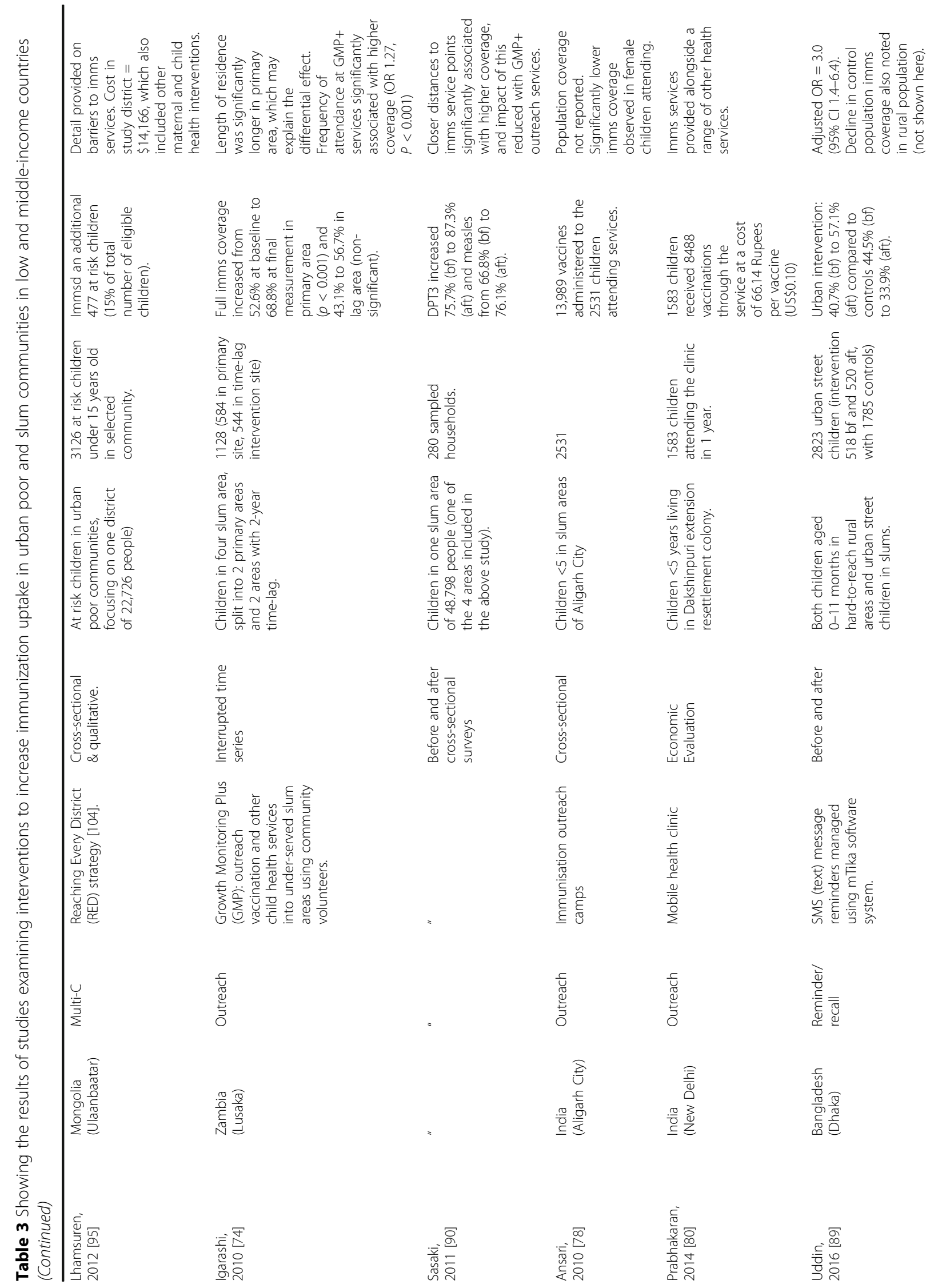




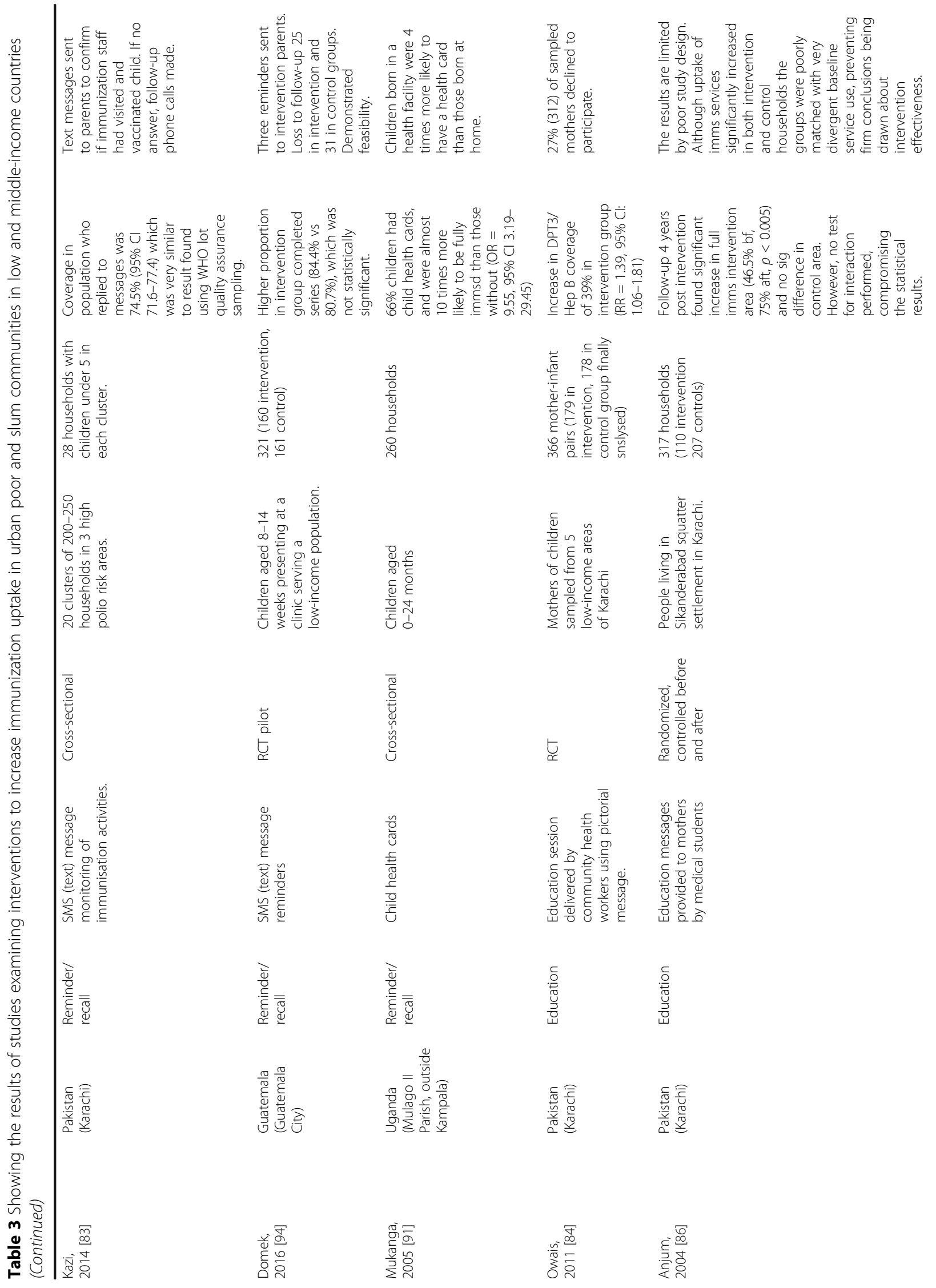




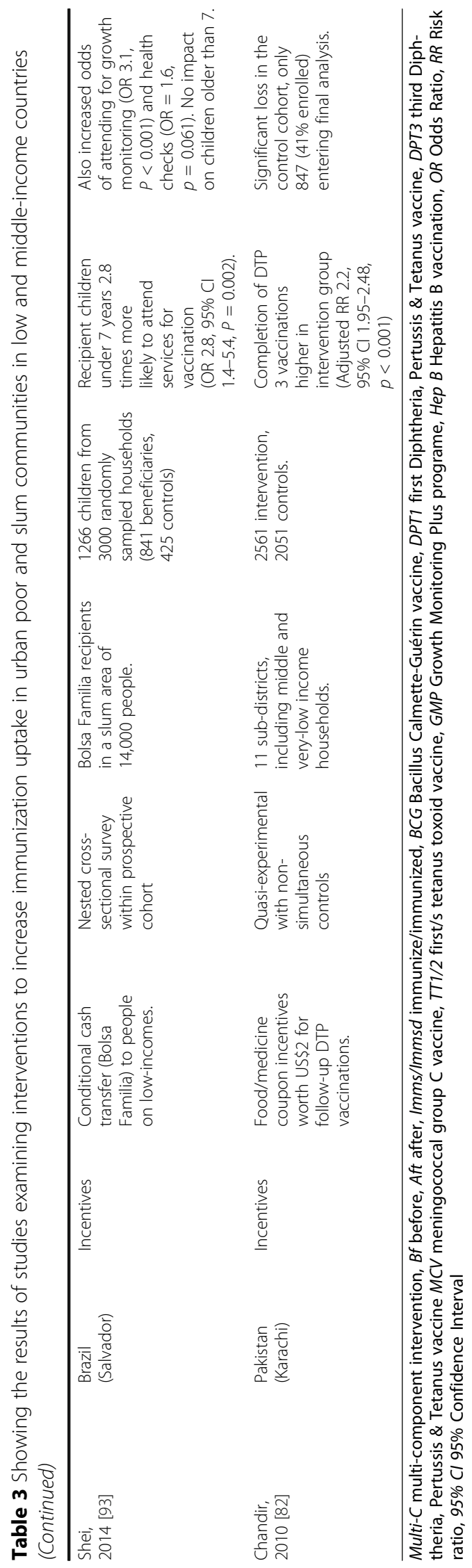


of Patna, India, involving enhanced service delivery (outreach; additional nursing staff; task-shifting; geographic monitoring; community mobilization; supervision and communication components) was evaluated using before-and-after analysis of routinely collected data, and showed increases in immunization uptake e.g. DTP3 increased from $21 \%$ to $49 \%$, MCV from $23 \%$ to $51 \%$ [81]. Another study evaluated the Urban Health Programme (combining demand and supply side interventions with increased clinic accessibility and community involvement) in Indore, India, which showed an increase in complete immunization among infants from $32 \%$ to $72 \%$ [77].

Two studies considered typhoid vaccination specifically. A cluster RCT involving 21,059 children was conducted in squatter communities in Karachi, Pakistan, to evaluate a campaign to increase typhoid vaccine coverage (involving information provision; community involvement; increased services; and staff training), which achieved $74 \%$ coverage in the target population, with maintenance of cold-chain [85]. A study in New Delhi, India, undertook economic analyses of different vaccination campaigns against typhoid and concluded that a targeted program for pre-school children was most costeffective (US\$14 per case averted), when compared to a school campaign (US\$41) or general mass campaign (US\$50) [96].

A large study $(n=161,695$ children $)$ in urban Nairobi and Nyanza provinces focusing on populations living in low-income, high-density environments demonstrated how the use of community volunteers calling door-to-door and providing standardized information using mobile phone technology can contribute to achieving high coverage (92\%) during a planned mass MCV campaign [92].

A study conducted in Ulaanbaatar City, Mongolia, reports a before-and-after analysis following the implementation of the 'Reaching Every District' (RED) strategy by the ministry of health in an urban poor community, which reached an additional 477 children at risk of underimmunization, $15 \%$ of the total eligible population in the entire district, and also improved organizational structures and staff motivation [95].

\section{Outreach programmes}

Two related studies reported on the Growth Monitoring Program Plus programme, which involved providing monthly outreach services implemented in periurban areas of Lusaka, Zambia [74, 90]. Comparing early implementation sites with late implementers, immunization coverage was shown to significantly increase in both areas, from $52.6 \%$ to $68.8 \%$ (early) and $43.1 \%$ to $56.7 \%$ (late), even after controlling for socioeconomic characteristics.
A study on an outreach services provided in Aligarh City, India, as part of a campaign reported success in immunizing over 2500 children in a low-income district and improving overall complete immunization coverage, demonstrating both feasibility and acceptability [78]. Another study in India provided descriptive evidence for the feasibility of providing vaccinations through a mobile health clinic in slum communities in Delhi, at the cost of RS66.14 per vaccine delivered (US\$0.10) [80].

\section{Reminder/recall}

Three studies have shown varying levels of success in the use of text message (SMS) systems. In Bangladesh, the use of SMS reminder system in both urban street dwellers and a rural 'hard-to-reach' population was evaluated [89]. The results showed an increase in coverage in both populations, with an adjusted odds ratio of complete immunization of 3.0 ( $95 \%$ confidence interval (CI): 1.4-6.4) among the urban children. In Pakistan, an SMS system was successfully used to monitor provision of polio immunization by asking urban community members to report whether their children had been immunized by vaccinators [83]. A proof-of-concept study in an urban poor community in Guatemala City showed that an SMS system to remind mothers to receive pentavalent vaccine was feasible and acceptable, but found no difference in vaccine uptake [94].

A study in a slum community in Uganda showed that children born at a health facility, or whose mother was unwell during the pregnancy were more likely to have an immunization reminder card, and that these children were 10 times more likely to be up to date for all immunizations when compared to children without cards [91].

\section{Education}

Two studies considered the effect of an intervention focussing on education or information provision to parents in Pakistan. An RCT conducted in Karachi involved community health workers delivering pictorial messages to encourage immunization [84]. The intervention resulted in a $39 \%$ increase (OR 1.39, 95\% CI: 1.06-1.81) of DTP3/Hepatitis B completion, although $27 \%$ of sampled women declined to take part. A randomized controlled before-and-after study of the provision of education sessions by medical students to mothers in a squatter settlement found an increase in complete immunization in the intervention group [86]. However, health centre utilisation for vaccination in intervention and control groups was significantly different at baseline (30\% vs $13 \%$ respectively), suggesting participants were poorly matched. Additionally, this study was excluded from a related Cochrane Review due to its poor study design [26], and thus provides only weak evidence for this intervention. 


\section{Incentives}

Two studies considered the effect of incentives on increasing vaccination uptake. A study of the Bolsa Familia program of conditional cash transfers in slums in Salvador City, Brazil, found that recipient families had higher use of health clinics and increased odds of vaccination uptake (OR 2.8; 95\% CI: 1.4-5.2) [93]. A study conducted in Pakistan involving nearly 4000 children investigated the effect of providing a coupon redeemable for food or medicine (worth US\$2) to incentivize attendance amongst low-income mothers in Karachi at follow-up immunization appointments [82]. The results showed increase (OR 2.2, 95\% CI: 1.95-2.48) in timely completion of the DTP immunization series

\section{Discussion}

A wide range of socio-economic and behavioural factors have been associated with immunization status in different slum and urban poor contexts. While some of this diversity may result from differences in study methods, much may also be from true differences in the factors in the underlying populations. One included study from Pakistan applied the same methods in multiple settings simultaneously and reached the conclusion that 'one size does not fit all', which is supported by the evidence in this review [60].

Further qualitative work is required to better understand the interlinking socioeconomic and demographic factors that influence immunisation coverage inequalities identified through analysis of surveys or population level data sources. The application of intersectionality theory, a method of systematically considering the multiple social labels individuals hold (e.g. ethnic group, gender, social class, migration status), may also provide additional useful detail in slum populations [97].

\section{Improving immunization coverage}

The evidence presented here demonstrates the relatively small number of interventional studies that have been conducted in slum populations. In addition, several of the studies have significant methodological flaws, requiring caution in the interpretation of the results. However, when comparing the evidence base identified here with the wider literature, it is notable that no interventions consider the importance of providing services to new migrants from rural areas in slum communities and that community involvement may be especially useful when designing interventions in slum areas.

A Cochrane review of interventions to improve coverage of childhood immunisation in low and middle income countries in all populations was published in 2014 also found a limited evidence base [26]. Of the studies described here, only one evaluating a maternal education programme was also included in the Cochrane review [84]. However, a comparison of the effectiveness for the type of interventions identified in this paper and in the Cochrane review are presented in Table 4.

Multi-component interventions that tackle multiple factors that can contribute to low coverage have some evidence for effectiveness [77, 81, 85, 88, 92, 95]. An important component was community involvement, which enables the individual context of a slum to be considered, although this was not identified separately in the Cochrane review. This should include consideration of minority ethnic groups, who may suffer from lower coverage [59, 67]. This matches similar research conducted in deprived urban communities in high-income countries [98].

The outreach programs identified in the literature focused specifically on reducing physical distance between communities and health services have evidence of effectiveness $[74,78,80,90]$. This finding matches that of a recent systematic review looking at improving immunization in LMIC urban areas generally, which concluded that outreach visits worked well in densely populated areas [99]. However, overall the authors identified fewer papers than are included in this study despite having a broader topic and longer time-frame. Outreach may be particularly

Table 4 A comparison of results for evidence of effectiveness of interventions to increase vaccination coverage in LMICs from a Cochrane review, [26] and in slum populations identified in this paper

\begin{tabular}{|c|c|c|}
\hline \multirow[t]{2}{*}{ Intervention type } & \multicolumn{2}{|l|}{ Strength of evidence of benefit } \\
\hline & Cochrane Review (general populations) & Slum populations \\
\hline Education & Moderate & Some evidence of potential benefit \\
\hline Education and reminder cards & Low & Not tested \\
\hline Household financial incentive & No effect & Some evidence of potential benefit \\
\hline Outreach and financial incentives & Low & Not tested \\
\hline Home visits & Low & Evidence of benefit, where distance is significant. \\
\hline Integrating immunisation with other health services & Low & Not tested \\
\hline Text messaging & Not tested & Some evidence of potential benefit \\
\hline Community involvement & Not tested & Important factor in effective studies. \\
\hline
\end{tabular}


relevant for slum communities, where there may be a lower density of health facilities, and should be a focus of further research.

No interventions were identified that reduced the social distance that some slum residents may experience when accessing health services. Specifically, no interventions were identified that provided services to migrants from rural areas, despite that migration was identified as having a universally negative effect on immunization coverage. Slums are often the first entry point of new migrants to an urban area [23], and the process of migration leads to an understandable disruption in parents' ability to access health services, leading to lower coverage $[53,71]$.

Reminder/recall systems have good evidence for effectiveness in high-income countries and are considered as a core component of any immunization programme [100]. However, the provision of reminder/recall systems in LMICs is challenging, especially in slums, due to informal road systems, lack of addresses and limited access to electronic communications. However, of the three studies presented here, two show that SMS reminders can be effective in a slum context, [83, 89] and the other showed feasibility as part of a pilot RCT, although found no difference in coverage [94].

Of the two studies evaluating education programmes identified here, one showed some evidence of effectiveness [84], but the other was compromised by methodological limitations [86]. However, community-based education programmes have evidence for effectiveness in increasing immunization uptake in LMICs generally and warrant further investigation in slum contexts [26]. The use of incentives is not supported by evidence from a recent Cochrane review of interventions to improve immunization in LMICs generally, unless incentives are combined with outreach [26]. However, both studies identified here had positive effects that also warrant further investigation $[82,93]$.

\section{Limitations}

The quality of the included studies was only poor to medium, with no high quality randomised trials, making assessment for risk of bias challenging. We included studies conducted in slums alongside other urban poor communities, which may not be commensurate. Few studies reported negative results, suggesting publication bias overall. Several studies reported in Chinese were excluded. No evidence was identified for many countries with significant slum-dwelling populations, such as Indonesia, the Philippines, Sudan, Mozambique and Madagascar.

\section{Conclusions}

Different factors affect immunization coverage in different urban poor and slum contexts. Immunization services should be designed and provided to slum-dwelling communities in consultation with the people living there, considering the local context and avoiding constructing barriers to access, such as geographic and social distance, cost and timing. Interventions should be designed and tested to increase immunization in new migrants from rural areas.

\section{Additional file}

Additional file 1: Search strategy. Search strategy. Description of data: search strategy used in Medline. (DOCX 18 kb)

\section{Abbreviations \\ CAR: Central African Republic; DRC: Democratic Republic of Congo; DTP3: Diphtheria, Tetanus, Pertussis vaccine, 3rd dose; LMIC: Low and Middle Income Countries; MCV: Measles Containing Vaccine; RCT: Randomized Controlled Trial; SE: Socio-economic; SMS: Short Message Service, text message; VPD: Vaccine Preventable Disease}

\section{Acknowledgements}

Not applicable.

\section{Funding}

TCB was funded to undertake this work through a grant from the Royal Society of Tropical Medicine and Hygiene. The funding body had no role in the design of the study, data collection, analysis, interpretation of production of the manuscript.

\section{Availability of data and materials}

The datasets used and analysed during the current study are available from the corresponding author on reasonable request.

\section{Authors' contributions}

TCB conceived the study with RD, and SMJ advised on the methods. TCB undertook the searches and titles for screening. TCB and GM and RD agreed final inclusions and undertook data extraction. TCB, GM, RD and SMJ contributed to write-up and editing of the final paper. All authors have read and approved the final version of this manuscript.

\section{Competing interests}

The authors declare that they have no competing interests.

Consent for publication

Not applicable.

Ethics approval and consent to participate

No ethical approval required, as this is a review of secondary data sources.

\section{Publisher's Note}

Springer Nature remains neutral with regard to jurisdictional claims in published maps and institutional affiliations.

\section{Author details}

${ }^{1}$ Health Protection Research Unit in Immunisation, Faculty of Public Health and Policy, London School of Hygiene and Tropical Medicine, 15-17

Tavistock Place, London WC1H 9SH, UK. ²Programme Division, Health

Section, UNICEF Headquarters, 3 United Nations Plaza, New York 10017, USA.

Received: 13 December 2016 Accepted: 28 May 2017

Published online: 08 June 2017

\section{References}

1. UN Habitat. World Cities Report 2016. Urbanization and Development: Emerging Futures. New York: Pub. United Nations; 2016.

2. United Nations. World Urbanization Prospects: 2014 Revision. New York: Pub. United Nations; 2014. 
3. Ezeh A, Oyebode O, Satterthwaite D, Chen Y, Ndugwa R, Sartori J, et al. The health of people who live in slums 1 - the history, geography, and sociology of slums and the health problems of people who live in slums. Lancet. 2016;6736(16):1-12.

4. Habitat III Conference. Quito Declaration on Sustainable Cities and Human Settlements for All. New York: Pub. United Nations; 2016.

5. United Nations. Sustainable Development Goals: 17 Goals to Transform Our World. 2016. http://www.un.org/sustainabledevelopment/. Accessed $6^{\text {th }}$ Sept 2016.

6. Hinman AR. Immunization equity. Vaccine. 2015;33:D72-7.

7. Sharma V, Singh A, Sharma V. Provider's and user's perspective about immunization coverage among migratory and non-migratory population in slums and construction sites of Chandigarh. J Urban Health. 2015; 92(2):304-12.

8. Fatiregun AA, Adebowale AS, Ayoka RO, Fagbamigbe AF. Assessing full immunisation coverage using lot quality assurance sampling in urban and rural districts of southwest Nigeria. Trans R Soc Trop Med Hyg. 2013;107(11): $731-40$

9. Kulkarni SV, Chavan MK. A study to assess the immunization coverage in an urban slum of Mumbai by lot quality technique. Int J Med Public Health. 2013:3:21-5.

10. Soura AB, Mberu B, Elungata P, Lankoande B, Millogo R, Beguy D, et al. Understanding inequities in child vaccination rates among the urban poor: Evidence from Nairobi and Ouagadougou health and demographic surveillance systems. J Urban Health. 2015;92(1):39-54.

11. Loening WE, Coovadia HM. Age-specific occurrence rates of measles in urban, peri-urban, and rural environments: Implications for time of vaccination. Lancet. 1983;2(8345):324-6.

12. Sharma MK, Bhatia V, Swami HM. Outbreak of measles amongst vaccinated children in a slum of Chandigarh. Indian J Med Sci. 2004;58(2):47-53.

13. Saha I, Haldar D, Paul B, Shrivastava P, Das DK, Pal M, et al. An epidemiological investigation of mumps outbreak in a slum of Kolkata. J Commun Dis. 2012; 44(1):29-36.

14. Lodha R, Dash NR, Kapil A, Kabra SK. Diphtheria in urban slums in north India. Lancet. 2000;355(9199):204.

15. Rahman SR, Ahmed MF, Islam MA, Rahman MM. Effect of risk factors on the prevalence of influenza infections among children of slums of Dhaka city. Spring. 2016;5

16. Breiman RF, Cosmas L, Njuguna H, Audi A, Olack B, Ochieng JB, et al. Population-based incidence of typhoid fever in an urban informal settlement and a rural area in Kenya: Implications for typhoid vaccine use in Africa. PLoS One. 2012;7(1):e29119.

17. Sur D, von Seidlein L, Manna B, Dutta S, Deb AK, Sarkar BL, et al. The malaria and typhoid fever burden in the slums of Kolkata, India: Data from a prospective community-based study. Trans R Soc Trop Med Hyg. 2006; 100(8):725-33.

18. Brooks WA, Hossain A, Goswami D, Nahar K, Alam K, Ahmed N, et al. Bacteremic typhoid fever in children in an urban slumBangladesh. Emerg Infect Dis. 2005;11(2):326-9.

19. Bahl R, Sinha A, Poulos C, Whittington D, Sazawal S, Kumar R, et al. Costs of illness due to typhoid fever in an Indian urban slum community: Implications for vaccination policy. J Health Popul Nutr. 2004;22(3):304-10.

20. Howie SRC, Schellenberg J, Chimah O, Ideh RC, Ebruke BE, Oluwalana C, et al. Childhood pneumonia and crowding, bed-sharing and nutrition: A casecontrol study from the Gambia. Int J Tuberc Lung Dis. 2016;20(10):1405-15,

21. Aaby P. Is susceptibility to severe infection in low-income countries inherited or acquired? J Intern Med. 2007;261(2):112-22.

22. UN Habitat. The Challenge of Slums: Global Report on Human Settlements 2003. New York: Pub. United Nations; 2003.

23. Roy D, Lees MH, Palavalli B, Pfeffer K, Sloot MAP. The emergence of slums: A contemporary view on simulation models. Environ Model Softw. 2014; 59(2014):76-90.

24. Moher D, Liberati A, Tetzlaff J, Altman DG. Preferred reporting items for systematic reviews and meta-analyses: The PRISMA statement. BMJ. 2009; 21(339):b2535

25. World Bank. Low \& middle income | Data. 2016. http://data.worldbank.org/ income-level/low-and-middle-income?view=chart. Accessed $27^{\text {th }}$ July 2016

26. Oyo-Ita A, Wiysonge CS, Oringanje C, Nwachukwu CE, Oduwole $\mathrm{O}$, Meremikwu MM, et al. Interventions for improving coverage of childhood immunisation in low- and middle-income countries (Review). Cochrane database Syst Rev. 2016;(7):CD008145.
27. Sridhar S, Maleq N, Guillermet E, Colombini A, Gessner BD. A systematic literature review of missed opportunities for immunization in low- and middle-income countries. Vaccine. 2014;32(51):6870-9.

28. Fotso J-C, Ezeh AC, Madise NJ, Ciera J. Progress towards the child mortality millennium development goal in urban sub-Saharan Africa: The dynamics of population growth, immunization, and access to clean water. BMC Public Health. 2007;7:218

29. Agarwal S, Bhanot A, Goindi G. Understanding and addressing childhood immunization coverage in urban slums. Indian Pediatr. 2005;42(7):653-63.

30. Mathew JL. Inequity in childhood immunization in India: A systematic review. Indian Pediatr. 2012;49(3):203-23.

31. Peng G, Liang S, Carlton EJ, QingWu J, Wu JY, Lei W, et al. Urbanisation and health in China. Lancet. 2012;379(9818):843-52.

32. Awoh $A B$, Plugge $E$. Immunisation coverage in rural-urban migrant children in low and middle-income countries (LMICS): a systematic review and metaanalysis. J Epidemiology \& Community Health. 2016;70:305-11.

33. Levin A, Kaddar M. Role of the private sector in the provision of immunization services in low- and middle-income countries. Health Policy Plan. 2011;26(suppl 1):i4-12.

34. Wiysonge CS, Uthman OA, Ndumbe PM, Hussey GD. Individual and contextual factors associated with low childhood immunisation coverage in sub-Saharan Africa: A multilevel analysis. PLoS One. 2012;7(5):e37905.

35. Rainey JJ, Watkins M, Ryman TK, Sandhu P, Bo A, Banerjee K, et al. Reasons related to non-vaccination and under-vaccination of children in low and middle income countries: Findings from a systematic review of the published literature, 1999-2009. Vaccine. 2011;29(46):8215-21.

36. Lassi ZS, Bhutta ZA. Community-based intervention packages for reducing maternal and neonatal morbidity and mortality and improving neonatal outcomes. Cochrane Database Syst Rev. 2015;3:CD007754.

37. Maketa V, Vuna M, Baloji S, Lubanza S, Hendrickx D, Inocencio da Luz RA, et al. Perceptions of health, health care and community-oriented health interventions in poor urban communities of Kinshasa, Democratic Republic of Congo. PLoS One. 2013;8(12):e84314.

38. Agarwal S. The state of urban health in India; comparing the poorest quartile to the rest of the urban population in selected states and cities. Environ Urban. 2011;23(1):13-28.

39. Kadarkar KS, Velhal GD. Lots quality coverage survey technique for assessment of determinants of immunization coverage in urban slum of Mumbai. Natl J Community Med. 2016;7:165-70.

40. Awasthi A, Pandey C, Singh U, Kumar S, Singh T. Maternal determinants of immunization status of children aged 12-23 months in urban slums of Varanasi, India. Clin Epidemiol Glob Heal. 2015:3(3):110-6.

41. Khan Q, Sinha T, Shrivastatva P, Brahmapurkar K, Brahmapurkar V. Assessment of immunization status among children aged 12-23 months, at an urban slum area of Jagdalpur city, Bastar. Healthline. 2015;6:55-60.

42. Kulkarni P, Hamid HSS, Shah M. Immunisation coverage status and reasons for underimmunisation in urban slums of Hyderabad city, Telangana state Indian. J Basic Appl Med Res. 2014;3:152-7.

43. Patel P, Desai K, Modi B, Bansal RK. Urban slums are new and important areas for inequalities in maternal and newborn health in many areas. Turk Silahl Kuvvetleri, Koruyucu Hekimlik Bulteni. 2014:13:217-24.

44. Agarwal N, Sharma RP, Chandra S, Varma P, Midha T, Nigam S. Immunization status and childhood morbidities as determinants of PEM among under-five children in slums of Kanpur, Indian. J Community Health. 2014;26:396-400.

45. Trivedi R, Singh S, Adhikari P, Jatav DP. Coverage evaluation of primary immunization and the associated determinants in an urban slum of Rewa, Indian. J Community Health. 2014;26:37-40.

46. Arokiasamy P, Jain $\mathrm{K}$, Goli S, Pradhan J. Health inequalities among urban children in India: A comparative assessment of empowered action group (EAG) and south Indian states. J Biosoc Sci. 2012:45(2):167-85.

47. Angadi MM, Jose AP, Udgiri R, Masali KA, Sorganvi V. A study of knowledge, attitude and practices on immunization of children in urban slums of Bijapur city, Karnataka, India. J Clin Diagn Res. 2013;7(12):2803-6.

48. Prakash $R$, Kumar A. Urban poverty and utilization of maternal and child health care services in India. J Biosoc Sci. 2013;45(4):433-49.

49. Wadgave HV, Pore PD. Missed opportunities of immunization in under-fives in adopted area of urban health Centre. Ann Trop Med Public Health. 2012; 5:436-40.

50. Sachdeva S, Datta U. Hepatitis B immunization coverage evaluation amongst slum children, Indian. J Public Health Res Dev. 2012;3:191-4. 
51. Ghei K, Agarwal S, Subramanyam MA, Subramanian SV. Association between child immunization and availability of health infrastructure in slums in India. Arch Pediatr Adolesc Med. 2010;164(3):243-9.

52. Jain T, Jai Veer S, Manjul B, Sunil Kumar G, Harivansh G, Shailendra Kumar B, et al. A cross sectional study on the coverage of immunization in the slums of western Uttar Pradesh, India. J Clin Diagn Res. 2010;4:3480-3.

53. Kusuma YS, Kumari R, Pandav CS, Gupta SK. Migration and immunization: Determinants of childhood immunization uptake among socioeconomically disadvantaged migrants in Delhi, India. Trop Med Int Health. 2010;15(11):1326-32.

54. Nath B, Singh JV, Awasthi S, Bhushan V, Kumar V, Singh SK, et al. A study on determinants of immunization coverage among 12-23 months old children in urban slums of Lucknow district, India. Indian J Med Sci. 2007;61(11):598-606.

55. Mathew JL, Babbar H, Yadav S. Reasons for non-immunization of children in an urban, low income group in North India. Trop Dr. 2002;32(3):135-8.

56. Kar M, Reddaiah VP, Kant S. Primary immunization status of children in slum areas of South Delhi - the Challange of Reaching the urban poor. Indian J Community Med. 2001;26(3):151

57. Desai V, Kapadia S, Kumar P, Nirupam S. Study of measles incidence and vaccination coverage in slums of surat city. Indian J Community Med. 2003; 28(1):10-4.

58. Nath B, Singh JV, Awasthi S, Bhushan V, Singh SK, Kumar V. Client satisfaction with immunization services in urban slums of Lucknow district. Indian J Pediatr. 2009;76(5):479-83.

59. Siddiqui NT, Owais A, Agha A, Karim MS, Zaidi AKM. Ethnic disparities in routine immunization coverage: A reason for persistent poliovirus circulation in Karachi, Pakistan? Asia Pac J Public Health. 2014;26(1):67-76.

60. Cockcroft A, Andersson N, Omer K, Ansari NM, Khan A, Chaudhry UU, et al. One size does not fit all: Local determinants of measles vaccination in four districts of Pakistan. BMC Int Health Hum Rights. 2009;9(suppl 1):S4.

61. Adil M, Zubair M, Alam A, Khan S, Ishtiaque Z, Quereshi A. Knowledge of mothers about children's immunization status in the urban areas of Islamabad. Rawal Medical J. 2009:34:33-5.

62. Joulaei H, Bhuiyan AR, Sayadi M, Morady F, Afsar Kazerooni P, et al. Slums' access to and coverage of primary health care services: A cross-sectional study in shiraz, a metropolis in southern iran. Iran J Med Sci. 2014;39(2 suppl):184-90.

63. Sun M, Ma R, Zeng Y, Luo F, Zhang J, Hou W. Immunization status and risk factors of migrant children in densely populated areas of Beijing, China. Vaccine. 2010;28:1264-74.

64. Egondi T, Oyolola M, Mutua MK, Elung'ata P. Determinants of immunization inequality among urban poor children: Evidence from Nairobi's informal settlements. Int J Equity Health. 2015;14(1):24.

65. Maina LC, Karanja S, Kombich J. Immunization coverage and its determinants among children aged 12-23 months in a peri-urban area of Kenya. Pan Afr Med J. 2013;14:3.

66. Mutua MK, Kimani-Murage E, Ettarh RR. Childhood vaccination in informal urban settlements in Nairobi, Kenya: Who gets vaccinated? BMC Public Health. 2011;11(1):6.

67. Ettarh RR, Mutua MK, Kyobutungi C. Ethnicity and delay in measles vaccination in a Nairobi slum. Trop Med Health. 2012;40(2):59-62.

68. Borus PK. Missed opportunities and inappropriately given vaccines reduce immunisation coverage in facilities that serve slum areas of Nairobi. East Afr Med J. 2004;81(3):124-9.

69. Sadoh AE, Sadoh WE, Uduebor J, Ekpebe P, Iguodala O. Factors contributing to delay in commencement of immunisation in Nigerian infants. Tanzan J Health Res. 2013;15(3):186-92.

70. Onwujekwe O, Hanson K, Uzochukwu B. Are the poor differentially benefiting from provision of priority public health services? A benefit incidence analysis in Nigeria. Int J Equity Health. 2012;11(1):70.

71. Antai D. Migration and child immunization in Nigeria: Individual- and community-level contexts. BMC Public Health. 2010;10:116.

72. Mohamud AN, Feleke A, Worku W, Kifle M, Sharma HR. Immunization coverage of 12-23 months old children and associated factors in Jigjiga District, Somali National Regional State, Ethiopia. BMC Public Health. 2014;14:865.

73. Bobossi-Serengbe G, Fioboy R, Ndoyo J. Missed opportunities for immunization in children of 0 to 11 months in Bangui. J Pediatr Pueric. 2014;27:289-93.

74. Igarashi K, Sasaki S, Fujino Y, Tanabe N, Muleya CM, Tambatamba B, et al. The impact of an immunization programme administered through the growth monitoring programme Plus as an alternative way of implementing integrated Management of Childhood IInesses in urban-slum areas of Lusaka, Zambia. Trans R Soc Trop Med Hyg. 2010;104(9):577-82.
75. Konstantyner T, de AC TJA, Rodrigues LC. Risk factors for incomplete vaccination in children less than 18 months of age attending the nurseries of day-care centres in Sao Paulo, Brazil. Vaccine. 2011;29(50):9298-302.

76. Barata RBR, MCSdeA R, de Moraes JC, Flannery B, Group VCS 2007. Socioeconomic inequalities and vaccination coverage: Results of an immunisation coverage survey in 27 Brazilian capitals, 2007-2008. J Epidemiol Community Health. 2012;66(10):934-41.

77. Agarwal S, Satyavada A, Patra P, Kumar R. Strengthening functional community-provider linkages: Lessons from the Indore urban health programme. Glob Public Health. 2008;3(3):308-25.

78. Ansari M, Khan Z. Routine immunization coverage in underserved children of Aligarh (India): An effort with UNICEF. J Child Health Care. 2010;14(2):142-50

79. Botham SJ, Poulos RG, McFarland KJ, Ferson MJ. Getting it right-the Australian childhood immunisation register and immunisation rates in south-eastern Sydney. Aust N Z J Public Health. 2004:28(1):68-71.

80. Prabhakaran A, Krishnan A, Nongkynrih B, Goswami A, Pandav CS. Cost of ambulatory care by mobile health clinic run by a medical College in India for the year 2008-09. Indian J Public Health. 2014;58(2):100-5.

81. Pradhan N, Ryman TK, Varkey S, Ranjan A, Gupta SK, Krishna G, et al. Expanding and improving urban outreach immunization in Patna, India. Trop Med Int Health. 2012:17(3):292-9.

82. Chandir S, Khan AJ, Hussain H, Usman HR, Khowaja S, Halsey NA, et al. Effect of food coupon incentives on timely completion of DTP immunization series in children from a low-income area in Karachi, Pakistan: A longitudinal intervention study. Vaccine. 2010;28(19):3473-8.

83. Kazi AM, Murtaza A, Khoja S, Zaidi AK, Ali SA. Monitoring polio supplementary immunization activities using an automated short text messaging system in Karachi, Pakistan. Bull World Health Organ. 2014;92(3):220-5.

84. Owais A, Hanif B, Siddiqui AR, Agha A, Zaidi AKM. Does improving maternal knowledge of vaccines impact infant immunization rates? A communitybased randomized-controlled trial in Karachi, Pakistan. BMC Public Health. 2011;11:239.

85. Khan MI, Ochiai RL, Hamza H Bin, Sahito SM, Habib MA, Soofi SB, et al. Lessons and implications from a mass immunization campaign in squatter settlements of Karachi, Pakistan: An experience from a cluster-randomized double-blinded vaccine trial [NCT00125047]. Trials. 2006;7(17):1-10.

86. Anjum Q, Omair A, Inam SNB, Ahmed Y, Usman Y, Shaikh S, et al. Improving vaccination status of children under five through health education. J Pak Med Assoc. 2004;54(12):610-3.

87. Hayford K, Uddin MJ, Koehlmoos TP, Bishai DM. Cost and sustainability of a successful package of interventions to improve vaccination coverage for children in urban slums of Bangladesh. Vaccine. 2014;32(20):2294-9.

88. Uddin MJ, Larson CP, Oliveras E, Khan Al, Quaiyum MA, Saha NC, et al. Child immunization coverage in urban slums of Bangladesh: Impact of an intervention package. Health Policy Plan. 2010;25(1):50-60.

89. Uddin MJ, Shamsuzzaman M, Horng L, Labrique A, Vasudevan L, Zeller K, et al. Use of mobile phones for improving vaccination coverage among children living in rural hard-to-reach areas and urban streets of Bangladesh. Vaccine. 2016:34:276-83.

90. Sasaki S, Igarashi K, Fujino Y, Comber AJ, Brunsdon C, Muleya CM, et al. The impact of community-based outreach immunisation services on immunisation coverage with GIS network accessibility analysis in peri-urban areas, Zambia. J Epidemiol Community Health. 2011;65(12):1171-8.

91. Mukanga DO, Kiguli S. Factors affecting the retention and use of child health cards in a slum community in Kampala, Uganda, 2005. Matern Child Health J. 2006;10(6):545-52.

92. Mbabazi WB, Tabu CW, Chemirmir C, Kisia J, Ali N, Corkum MG, et al. Innovations in communication technologies for measles supplemental immunization activities: Lessons from Kenya measles vaccination campaign, November 2012. Health Policy Plan. 2015;30(5):638-44.

93. Shei A, Costa F, Reis MG, Ko Al. The impact of Brazil's Bolsa Familia conditional cash transfer program on children's health care utilization and health outcomes. BMC Int Health Hum Rights. 2014;14(1):10.

94. Domek GJ, Contreras-Roldan IL, O'Leary ST, Bull S, Furniss A, Kempe A, et al, SMS text message reminders to improve infant vaccination coverage in Guatemala: A pilot randomized controlled trial. Vaccine. 2016:34: 2437-43.

95. Lhamsuren K, Choijiljav T, Budbazar E, Vanchinkhuu S, Blanc DC, Grundy J, et al. Taking action on the social determinants of health: Improving health access for the urban poor in Mongolia. International Journal for Equity in Health. 2012;11:1-10. 
96. Poulos C, Bahl R, Whittington D, Bhan MK, Clemens JD, Acosta CJ. A costbenefit analysis of typhoid fever immunization programmes in an Indian urban slum community. J Health Popul Nutr. 2004;22(3):311-21.

97. Joe W. Intersectional inequalities in immunization in India, 1992-93 to 200506: A progress assessment. Health Policy Plan. 2015;30(4):407-22.

98. Crocker-Buque T, Edelstein M, Mounier-Jack S. Interventions to reduce inequalities in vaccine uptake in children and adolescents aged $<19$ years: A systematic review. J Epidemiol Community Health. 2017;71(1):87-97.

99. Nelson KN, Wallace AS, Sodha SV, Daniels D, Dietz V. Assessing strategies for increasing urban routine immunization coverage of childhood vaccines in low and middle-income countries: A systematic review of peer-reviewed literature. Vaccine. 2016;34(46):5495-503.

100. Harvey H, Reissland N, Mason J. Parental reminder, recall and educational interventions to improve early childhood immunisation uptake: A systematic review and meta-analysis. Vaccine. 2015;33(25):2862-80.

101. Damor RD, Pithadia PR, Lodhiya KK, Mehta JP, Yadav SB. A study on assessment of nutritional and immunization status of under-five children in urban slums of Jamnagar city, Gujarat. Healthline. 2013;4:35-9.

102. Gupta SK, Nandeshwar S. Status of maternal and child health and services utilization patterns in the urban slums of Bhopal, India. Natl J Community Med. 2012;3:330-2.

103. Sharma R, Desai VK, Kavishvar A. Assessment of immunization status in the slums of Surat by 15 clusters multi indicators cluster survey technique. Indian J Community Med. 2009;34(2):152-5.

104. WHO UNICEF. Microplanning for immunization service delivery using the Reaching Every District (RED) strategy. New York: Pub. WHO; 2009.

105. WHO. Global Health Observatory Data: Urban health. 2016. http://www.who. int/gho/urban_health/en/. Accessed 6 Sept 2016.

\section{Submit your next manuscript to BioMed Central and we will help you at every step:}

- We accept pre-submission inquiries

- Our selector tool helps you to find the most relevant journal

- We provide round the clock customer support

- Convenient online submission

- Thorough peer review

- Inclusion in PubMed and all major indexing services

- Maximum visibility for your research

Submit your manuscript at www.biomedcentral.com/submit

C) Biomed Central 